\title{
DISCURSO DEL RECTOR DE LA UNIVERSIDAD CATÓLICA DEL NORTE SR. JUAN ANDRÉS MUSIC TOMICIC
}

Esta es una fecha de especial significación para la Universidad Católica del Norte particularmente para su Escuela de Derecho de la Sede Coquimbo, con motivo del egreso de sus primeros 14 alumnos.

Hace ya cinco años, en mi calidad de Rector de esta Casa de Estudios Superiores, tuve el privilegio de tener directa participación en la creación de esta carrera, razón por la cual no puedo menos que expresar la gran satisfacción que hoy siento al ver culminar con éxito la primera etapa de formación de profesionales en esta área del saber, anhelo éste que, en su oportunidad, se percibía como un gran sueño y desafío.

La Universidad Católica del Norte ha asumido desde su creación en 1956 un compromiso con el desarrollo del país y muy especialmente contribuir al progreso del Norte Chileno al cual aporta su quehacer académico para el engrandecimiento de los habitantes de las regiones, de Antofagasta y Coquimbo especialmente.

Es importante recordar en esta ocasión, lo que nos propusimos como uno de nuestros objetivos el año 1992, en relación a que debíamos incrementar y diversificar las ofertas educacionales de pregrado, postgrado y educación continua que la Universidad ofrece a los estudiantes que egresan cada año de la enseñanza media y a los profesionales que buscan mayor perfeccionamiento durante su vida laboral, en un mundo donde el conocimiento está cambiando a gran velocidad y exige a todos un continuo reciclaje y profundización de ellos.

Deseo recordar que al inicio de 1990, nuestra Universidad contaba con un universo estudiantil de pregrado de 2.877 alumnos para 15 ofertas educacionales a la juventud, no contando a esa fecha con ningún programa de postgrado.

A partir de la situación antes descrita, la Universidad lleva a cabo un plan de expansión académica, que ha significado que hoy ofrezcamos a la juventud un total de 29 carreras de pregrado y 5 programas de postgrado, contribuyendo con ellos a que cada día una mayor cantidad de estudiantes pueda continuar sus estudios universitarios en la propia región en que viven, lo que significa un aporte concreto al proceso de descentralización del país y al desarrollo de las regiones.

Considero oportuno mencionar en esta ocasión tan importante cual ha sido esta diversificación de carreras que la Universidad, en forma responsable, ha llevado a cabo.

Desde 1990 a la fecha hemos creado en Antofagasta las carreras de : Derecho, Ingeniería Civil Industrial, Ingeniería Civil Metalúrgica, Periodismo, Psicología, Química Ambiental, Química en Metalurgia Extractiva, Pedagogía en Matemáticas y Computación, Ingeniería de Ejecución en Procesos Químicos e Ingeniería de Ejecución Metalúrgica. 
En el caso de la Sede Coquimbo, se han creado las carreras de : Ingeniería Comercial, Licenciatura en Ciencias Religiosas, Pedagogía en Filosofía y Religión y Derecho.

Toda esta expansión ha hecho posible que hoy el universo estudiantil de la Universidad, sea de 6.500 jóvenes y en el caso de la Sede Coquimbo, alcance a 1.450 alumnos en las 6 carreras que hoy se ofrecen en esta Región.

En el marco y políticas antes descrito, debemos destacar la carrera de Derecho que hoy entrega sus primeros egresados.

Desde la creación de la Escuela de Derecho, ésta ha contado con una clara, visionaria y excelente dirección, que se ha comprometido con el proyecto y junto a un selecto grupo de profesores y entusiastas estudiantes, que creyeron en él. Ello permite esta tarde sentirnos orgullosos al constatar que el sueño y proyecto diseñado se hizo realidad, y que la Universidad Católica del Norte puede mostrar orgullosa una Escuela de Derecho en la IV Región, que ha logrado exitosamente posesionarse entre sus pares más destacados. ¡Felicitaciones por este logro!.

Todo proyecto para su materialización y buen funcionamiento, requiere contar con el apoyo no sólo de la Universidad, sino especialmente de los habitantes, autoridades e instituciones existentes en la región, donde se está desarrollando.

Es por ello, que hoy es el momento de agradecer a todos los que generosa y desinteresadamente nos han apoyado y alentado durante todo este tiempo.

Vaya en primer lugar mi reconocimiento a toda la comunidad de la IV Región, en la cual siempre hemos encontrado una excelente acogida para esta Carrera de gran tradición en la sociedad chilena.

Agradezco también a los estudiantes de nuestra Escuela de Derecho, que con su entusiasmo y dedicación han contribuido a prestigiar esta carrera. A ellos y en especial a los que hoy egresan de nuestras aulas, les recordamos que su futuro ejercicio profesional, permitirá que la sociedad evalúe la formación que les hemos entregado. Estamos seguros que esta evaluación será muy positiva.

A todos los profesores que durante estos cinco años, nos han acompañado en esta gestión formativa, quienes no sólo han hecho su contribución académica sino que, además, han demostrado un profundo compromiso con el proyecto de formación de nuestros alumnos y de la labor de difusión y de extensión que hemos podido realizar.

Al Gobierno Regional, en la persona de su Intendente Don Renán Fuentealba Moena, quien desde los inicios de esta Escuela ha estado preocupado de su desarrollo, colaborándonos en cuanto le ha sido posible ya sea desde su alta investidura pública o como particular.

Toda Escuela de Derecho, por su naturaleza, requiere para su buen funcionamiento del apoyo de todas las instituciones directamente relacionadas con la profesión, es por ello que deseo muy sinceramente destacar y agradecer la excelente disposición y apoyo real que hemos tenido de parte de la llustrísima Corte de Apelaciones de La Serena, del Colegio de Abogados de la Región de Coquimbo, la Asociación Regional de Magistrados y del Círculo de Mujeres Abogados. 
Este Rector, en nombre propio y de la institución que representa, les agradece toda su valiosa cooperación y les solicita muy sinceramente que ésta continúe en el tiempo, porque trabajando juntos es posible seguir engrandeciendo esta Escuela.

Todo proyecto exitoso cuenta siempre con un líder, una persona que irradia el optimismo, requisito fundamental de éxito, y es por ello que deseo expresar mi más profundo reconocimiento, sincera gratitud y felicitaciones a nombre propio como de la Universidad a quien no sólo fue la creadora de este proyecto, sino su gran conductora y única Directora. Me refiero a la Sra. Luz María Reyes Santelices quien, desde los inicios de esta carrera, ha ocupado el cargo de Directora de la Escuela de Derecho no sólo con singular creatividad sino también, demostrando especiales dotes para saber obtener el compromiso de toda la comunidad regional en el desarrollo de esta empresa que hoy rinde sus primeros frutos con el egreso de su primera promoción.

Estimados alumnos: Hoy que dejan nuestras aulas, tengan presente que esta es sólo una primera etapa de su formación profesional, la que deberá ser complementada con las actividades de titulación propias de la carrera hasta la obtención de su título profesional que les otorgará la Excelentísima Corte Suprema de Justicia. La formación que les hemos entregado, estamos ciertos les permitirá desarrollar una labor profesional no sólo de buena calidad sino que imbuida en los sólidos principios de la fe católica que rige nuestra actividad educacional.

¡Que Dios los ilumine a todos!

Muchas Gracias. 